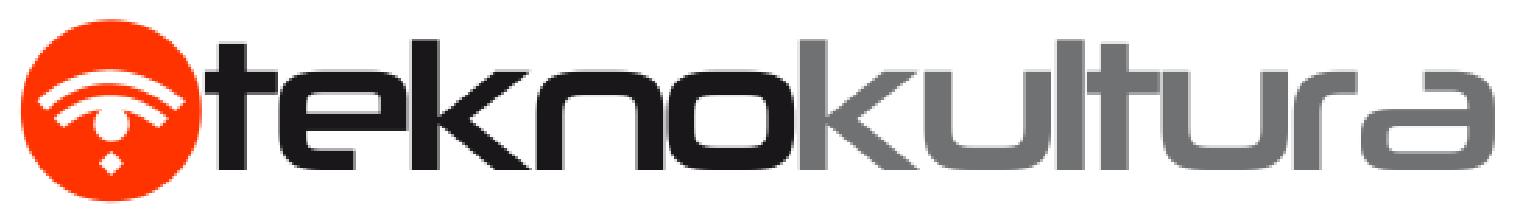

\#Serrano Muñoz, E. y Cabello Fernández-Delgado, F. (2015). Crisis y cibermundo: Mutaciones históricas entre cibercapitalismo y postcapitalismo. Revista Teknokultura, Vol. 12(2), 337-363.

Recibido: 17-12-2014

Aceptado: 22-07-2015
Open peer review

http://revistas.ucm.es/index.php/TEKN/pages/view/opr-49671

\title{
Crisis y cibermundo: Mutaciones históricas entre cibercapitalismo y postcapitalismo
}

\author{
Eduardo Serrano Muñoz y Florencio Cabello Fernández-Delgado \\ Universidad de Sevilla - Universidad de Málaga \\ tatotete@gmail.com - fcabello@uma.es
}

\section{Resumen}

Este artículo aborda el vínculo entre el devenir social en el cibermundo y los dispositivos tecnológicos a su servicio con el fin de interpretar las relaciones de poder que atraviesan la actual crisis sistémica y, más allá, las emergentes formas de producción social vinculadas al tercer sector, basadas en el procomún y que toman internet como un campo privilegiado de batalla. A partir de aquí, se exploran cuatro asuntos fundamentales: los modos de construcción de los espacios de convivencia y los recursos que sostienen dicha 
producción social; los modos de relación con el ciberterritorio que permiten a sus habitantes ser protagonistas en el mismo, y no meros espectadores pasivos; las potencialidades y vulnerabilidades del cibermundo, y sus implicaciones emancipatorias o controladoras; y las contradicciones que plantean las nuevas formas económicas y sociales frente a los principios de la sociedad del capital. Como conclusión, se apuntan los riesgos de cercamiento y apropiación masiva de la creatividad social, así como las perspectivas de aprovechamiento comunal de la riqueza social presentes en las experiencias más acabadas de economía híbrida.

\title{
Palabras Clave
}

Procomún, producción social, economías híbridas, cibermundo, cibercapitalismo, redes sociales.

\begin{abstract}
This paper tackles the connection between the social transformations in the cyberworld and the technologies at their service as an attempt to understand the power relations present in the current economic crisis and the emerging third-sector, commons-based social production taking the internet as a privileged battlefield. Building on this, four main topics are explored and discussed: how the spaces of cohabitation and the resources that sustain the social production are built; how the inhabitants of the cyberterritory relate with it so as to gain prominence in its construction; what are the potentialities and vulnerabilities of the cyberworld with a view to social emancipation or control; and the contradictions appearing in the new economic and social forms with respect to the principles of capitalist societies. To conclude, we point to the risks of enclosure and massive appropriation of the social creativity, as well as to the prospects of communal benefit of the social wealth present in the most successful experiences of hybrid economy.
\end{abstract}

\section{KEYWORDS}

Commons, social production, hybrid economies, cyberworld, cybercapitalism, social networking sites. 


\section{Sumario}

\section{Introducción}

La potencia de un nuevo territorio

La vida de las cosas

Cibermundo y geomundo

Ética

Las mediaciones y el capital

Cibercapitalismo

Conclusión

Referencias

\section{SUMmaRY}

Introduction

The potential of a new territory

The life of things

Cyberworld and geoworld

Ethics

Mediations and capital

Cybercapitalism

Conclusion

References 



\section{Introducción}

Este no es un artículo solo sobre la Red o cibermundo. Queremos ir más allá para analizar la relación entre el devenir social y los medios tecnológicos, pero no como siguen presentán dose en tantos discursos: ni como facilitación sin precedentes de las relaciones sociales por parte de agentes mediadores especializados (especialmente en el caso de las redes sociales), ni como determinismo tecnológico del desarrollo económico y social (Winner 2008: 33-53; 109-139).

Ocurre que buena parte de las relaciones de poder en nuestras sociedades se ejercen a través de medios tecnológicos (ibid.: 55-81; Winner, 1977: 317-325). No es un fenómeno nuevo, viene aconteciendo desde hace mucho tiempo y sigue aconteciendo hoy. Ello puede ilustrarse con dos temas que ahora se comentan brevemente, correspondiendo al ámbito social contemporáneo exterior al cibermundo y en segundo lugar a la sociedad pre-internet.

El primer tema alude a lo que encontramos en nuestra cotidianidad, engañosamente trivial, a poco que pongamos atención: el cúmulo inmenso de favores, regalos, cuidados, colaboraciones, préstamos y, en definitiva, intercambios y prestaciones de lo que desde una perspectiva mercantilista suelen llamarse bienes y servicios. Traman el tejido de relaciones sociales más inmediato, pero sin relación directa con la lógica económica convencional: «La producción social de bienes y servicios, tanto públicos como privados, es ubicua, aunque pase desapercibida, y unas veces sustituye y otras complementa la producción mercantil y estatal. Por expresarlo de modo extravagante, se trata de la materia oscura de nuestro universo de producción económica» (Benkler, 2015a: 159).

Esta concepción de la producción social como «materia oscura» se vuelve un problema cuando aquella se pone inadvertidamente al servicio de objetivos que no decidimos nosotros. Considerar estas innovaciones que empiezan a tener un gran desarrollo en el cibermundo, y en especial cómo se va a crear escasez donde no la hay, es fundamental para poder entender el contexto de la economía capitalista actual, así como las prácticas políticas asociadas.

El segundo tema se refiere a las técnicas organizativas de lo social que pertenecen a una cierta historia subterránea y constitutiva de determinadas formas de autogobierno: comunas, sociedades de mujeres, poblaciones de esclavos libertos, experiencias anarquistas, comunidades religiosas igualitarias, etc. A la misma categoría pertenecen los colectivos contemporáneos, formales o informales, que integran el universo del llamado tercer sector, 
que se apoyan en una base local, disponen de mecanismos de deliberación, gestión y ejecución explícitos, y en cambio un escaso desarrollo de la propiedad privada. Ello no es incompatible con la escalabilidad alcanzada con iniciativas como el software libre (ibid.: 101-106) o, más cercanamente, la cooperativa Mondragón (si bien sucesos como el cierre de la división de Fagor en 2013 reabrieron el debate sobre las condiciones de dicha escalabilidad para preservar los principios cooperativistas).

Lo que nos interesa del cibermundo es: 1) cómo se han construido los espacios de convivencia y los recursos que sostienen las prácticas de autonomía que disfrutamos; 2) de qué manera ese territorio hace que sus habitantes no sean meros espectadores pasivos de lo que ahí acontece; 3) entender qué hace posible su potencia incomparable y también su fragilidad, y cómo eso puede servir para liberar o para someter; 4) explorar las nuevas formas económicas y sociales que surgen y hasta qué punto contradicen los principios de la sociedad del capital.

\section{La potencia de un nuevo territorio}

\section{La vida de las cosas}

Cuando ciertas poblaciones (por ejemplo átomos radioactivos, de organismos vivos, de humanos) alcanzan una determinada cantidad en un espacio pequeño y propicio se producen espontáneamente fenómenos emergentes (la materia transmuta en energía, surgen ecosis temas vivos, aparecen o se disgregan comunidades humanas) que transforman a las mismas poblaciones, las hacen diferentes respecto lo que eran antes de dichos acontecimientos (Dunbar, 1993). Esa situación se conoce como masa crítica. Pero esa denominación sería inexacta si tenemos en cuenta que además es precisa una cercanía espacial; por eso el término apropiado podría ser densidad crítica.

Los procesos que se desencadenan son posibles por la mera proximidad, sin que se nece siten factores ni agentes externos. Por supuesto, sabemos que el medio que propicia los encuentros es importante, y en nuestro caso el espacio que hace que la densidad sea fértil es la combinación de internet y la web. Internet y la web acercan a las personas, hacen que nuestro mundo sea más denso. Buena prueba de ello es el renovado interés por los fenómenos de mundo pequeño que, más allá de las boutades de Milgram, se verifican desde hace casi dos décadas en los estudios empíricos sobre la topología de la Web y la dinámica de la «esfera pública en red» (ibid.: 253-346). 
Los abundantes elementos en copresencia, sean ideas, aplicaciones, datos o avatares hu manos, entran en combinaciones que hacen crecer exponencialmente la población en relación con el número de elementos presentes. Así se generan nuevos elementos o cibercuerpos entre los que hay simples mezclas o híbridos y mutantes verdaderos cada vez más complejos. El resultado es un estímulo constante a la creatividad y una riqueza cada vez mayor de todo tipo de instrumentos, siempre que se dé una condición fundamental: que los canales de comunicación no frenen las interrelaciones y no se limiten la producción, difu sión, reproducción, uso y transformación de los productos, lo cual nos remite de lleno al conflicto actual en torno a la «neutralidad de la Red» (ibid.: 281-283, 456).

Un ámbito especialmente importante de esta dinámica evolutiva es el que concierne a los medios expresivos que canalizan la comunicación entre máquinas y humanos y de humanos entre sí. En el principio de esta evolución había una comunicación exclusivamente discursiva confiada a los signos alfanuméricos; luego apareció el hipertexto, concepto central de la web y causante de un salto cualitativo de enorme importancia; progresivamente se han ido incorporando los medios audiovisuales, portadores de suntuosas sensualidades o de modos de conocer inéditos. Y lo que es todavía más importante, todo ello con grados cada vez mayores de operatividad e interoperabilidad por parte de los usuarios individuales o co lectivos y de los mismos cibercuerpos.

También suceden fenómenos emergentes en el peculiar espacio de los signos por el simple hecho de su cercanía espacial o temporal, lo cual se da de un modo específico en el interior del cibermundo: poder apreciar de un vistazo y poder mover y gestionar con un gesto del ratón o teclado (o del dedo) grandes conjuntos de signos de todo tipo (alfanuméricos, iconos, imágenes, acústicos) así como realizar y manejar composiciones complejas (párrafos, fórmulas, mapas, vídeos, diagramas, etc.), todo ello inmediatamente disponible, supone para nuestros instrumentos mentales un salto cualitativo, en línea con lo que uno de los padres de internet, Douglas Engelbart (1962: 5-6), denominaba el «intelecto humano aumentado».

Desde antiguo las cosas artificiales dan testimonios de su poder influyendo fuertemente en nuestras conductas: entrañables compañías, criaturas seductoras o rebeldes de irritante autonomía. A esas cosas de siempre se han sumado ahora múltiples cibercuerpos (pensemos en los virus) que, sin dejar de crecer y proliferar, han adquirido nuevas propiedades, por ejemplo movimientos semiautónomos (Winner, 1977). Una nueva especie ha ido afianzando su presencia a lo largo del siglo XX: las máquinas de máquinas, es decir, las máquinas que gobiernan a otras máquinas. Son las criaturas de Turing. 
La computación digitalizada supone el cruce de un umbral comparable al que se traspasó con la escritura alfabética, cuando los signos escritos ya no se remitían a las cosas sino a las voces que a través de las palabras nombran a las cosas (las palabras escritas alfabéticamente son entonces signos de signos). Con ello se produjo un notable efecto de exteriorización de los soportes de comunicación, de los procedimientos de cálculo y de la misma memoria, con una potencia muy superior a la de la escritura pictográfica. Ahora la escritura informática (signos de signos de signos, aunque sus referentes no sean cuerpos o cosas sino relaciones) produce ecosistemas semióticos de una especie diferente al del lenguaje natural con capacidades insólitas desde el momento en que producen acciones físicas sin pasar por un interpretante humano. A eso se añade la «web semántica» (Berners-Lee, Hendler \& Lassila, 2001; Hendler, Berners-Lee \& Miller, 2002), que aspira a ampliar extraordinariamente las relaciones entre los cibercuerpos a partir de sus propiedades y capacidades y al margen de la intervención de los agentes humanos. En definitiva, se trata de la exploración de un nuevo umbral de exteriorización y un nuevo grado de autonomía.

No se pueden igualar estas propiedades emergentes con las propias de los organismos vivos. Estaríamos tratando con un tipo diferente de vida que, no obstante, ya dispondría de la propiedad básica de afectar y ser afectado, en términos de Spinoza (2009). Convenir en la pertinencia de esta propiedad supone lo siguiente: 1) Pensar necesariamente en términos de colectividades, de conjuntos múltiples y complejos, no de objetos aislados; así las cosasen-el-mundo manifiestan su presencia, participan en acciones-reacciones, se juntan y separan; e igual que nosotros no son nada si están separadas unas de otras... y de nosotros. 2) Ambas condiciones van juntas, pues para reaccionar a la acción afectante es necesario ser afectado; y viceversa, para cualquier cuerpo no inerte no hay posibilidad alguna de motilidad sin que haya sensibilidad.

En términos más propios del cibermundo diremos que ser afectado y afectar implica tres tipos básicos de operaciones: recepción y emisión de información, a las que se suma una imprescindible actividad interna, el procesamiento de esa información. El resultado, no trivial, es que lo que sale es diferente a lo que entra. El procesamiento supone una interioridad compleja, una especie de ecosistema que se contrapone al ecosistema exterior con el que se conecta mediante recepción y emisión. Exigir que emisión y recepción no estén separadas, más la capacidad de procesar, es reivindicar una condición necesaria para su particular vida. Por ejemplo, nuestra potencia como habitantes de la Red se ve muy mermada por la asimetría que supone el hecho de que el operador de la infraestructura de comunicaciones imponga una velocidad de subida bastante inferior a la velocidad de descarga (lo que conocemos como ADSL, siglas de «asymmetric digital subscriber line»). 
Así muchos cibercuerpos sufren cambios en el curso de la transformación de la que son agentes; es decir aprenden y guardan memoria de aquellos procesos en los que están involucrados. A partir de aquí hay que diferenciar dos tipos de afecciones: las que están programadas o previstas, y aquellas que siendo posibles (más probables y efectivas en procesos en los que intervengan grandes poblaciones) comporten mutaciones aleatorias que abran las puertas a otros mundos: un principio de creatividad para esa comunidad que va creciendo a nuestro lado.

Donde se puede apreciar bien en qué consiste esta vida es en la comparación de los cibercuerpos de código fuente abierto y cerrado: lo que caracteriza a los segundos es su intangibilidad y consiguiente pseudovida, una existencia indefinida, siempre idénticos a sí mismos, haciendo inaccesible su código fuente protegido por la coraza de la propiedad intelectual. Bien diferente es el devenir de los productos con código fuente abierto: más que de copiarlos, se trata ahora de transformarlos (Lessig, 2009: 231-254). Su interacción con otras criaturas, humanas o no, introduce la historia en su vida: devenir indeterminista en vez de identidad determinada.

\section{Cibermundo y geomundo}

La singularidad del cibermundo en la vida social paulatinamente desaparece de nuestra consciencia a medida que la gente se acostumbra a habitarlo, y en paralelo internet va ha ciéndose coextensivo con los múltiples dominios del universo artificial y prepara ya su irrupción entre los organismos vivos. Podríamos convenir en denominar esa exterioridad del cibermundo como geomundo. La aproximación entre cibermundo y geomundo es, en definitiva, una consecuencia de la potencialidad de internet tal como ha sido concebida y construida hasta ahora. Un buen ejemplo de eso, que no por cercano es menos relevante, es la telefonía móvil, que se acopla cada vez más con nuestros sentidos corporales.

Esta composición se traduce en el crecimiento exponencial de la potencia de ambos mundos, también en el ámbito humano. Como señala Chris Kelty con respecto a las comuni dades de producción de software libre (los llamados «geeks»): «Los geeks son un caso interesante, precisamente, porque están involucrados en la creación de nuevas cosas que cambian el significado de nuestras categorías políticas constituidas. Su política se mezcla y se combina con detalles técnicos de Internet y del software libre, además de con las diversas y variadas organizaciones, leyes, personas y prácticas con las que conviven de manera regular: los sistemas operativos y los sistemas sociales» (Kelty, 2008: 94). En definitiva, diríamos que la potencia del sistema operativo (de orden técnico) incrementa la potencia del 
sistema social, y viceversa, formando un círculo virtuoso con bucles de retroalimentación en los dos sentidos, y eso dentro como fuera del cibermundo. La misma aparición de internet se debió a esa complicidad entre sistema operativo y sistema social (en este caso, el de los primeros internautas).

Con el advenimiento del cibermundo las cosas artificiales ganan poder (entendido como potencia), pues en el dominio del homo sapiens aparecen nuevos ecosistemas dotados cada vez con un mayor grado de autonomía. Un ejemplo de ello son los dispositivos telemáticos que desde hace años se están ensayando en los automóviles y que les permitirían comunicarse entre ellos y con otros artefactos. Es la conjunción progresiva de las máquinas matérico-energéticas con las computacionales la que está produciendo un mundo, aún apenas entrevisto, donde los humanos no ostentan el protagonismo exclusivo.

En esta dirección uno de los fenómenos emergentes más interesantes es la fabricación digital comunitaria, que permite que ciertos procesos industriales puedan descentralizarse y aproximarse a los usuarios, tanto en un sentido geográfico como instrumental, haciendo viable la fabricación de diseños muy singulares en series cortas o de un único ejemplar-prototipo. Hay ya ensayos para trasladar a la fabricación de objetos materiales los principios de composición productiva en red que se han usado con éxito en los sistemas operativos libres (el mayor ejemplo es GNU/Linux) y las aplicaciones informáticas correspondientes: procesos masivamente paralelos en que los diversos pasos no tienen que ajustarse a un orden rígido y preestablecido y los elementos componentes pueden producirse simultáneamente.

He aquí otra confirmación de que ese acoplamiento entre máquinas de Turing y máquinas matérico-energéticas (anunciado ya por el constituido por la capa lógica y la capa física) nos aproxima a un nuevo umbral tecnológico y a la vez social: al igual que antes se rompió la separación entre los pocos que podían emitir información y los muchos que solo la podían recibir, ahora empieza a ser concebible que se supere la barrera entre los pocos que pueden fabricar y diseñar y los muchos que solo pueden usar los bienes producidos.

Con todo, no debemos contemplar estos recientes fenómenos como estrictamente novedosos, sino como derivaciones de una composicición distribuida de la actividad humana que también ha propiciado fenómenos como la creación de monedas locales, la producción dis tribuida de energía o los procesos de participación política directa. La novedad es que el cibermundo proporciona un medio técnico barato, ubicuo, global y sumamente flexible para la superación de los estrechos límites operativos inherentes a los ámbitos donde han podido darse experiencias anteriores. Su expansión y proliferación podrían tener un efecto multiplicador con las consecuencias ya vistas en cuanto a los procesos autoalimentados y los fenómenos emergentes asociados. 
La conjunción del cibermundo con el geomundo es particularmente intensa en el caso del tercer sector, que agrupa multitud de actividades al margen de las administraciones públicas y de las empresas privadas. Las relaciones entre este tercer sector y las TIC son objeto de creciente interés por parte de las instituciones públicas. Un buen ejemplo es el informe donde A. Haché (2011: 51) define así el tercer sector «por un lado, como sociedad civil, entendida como ciudadanos que desarrollan sus actividades individualmente, sin estar motivados por la coerción o por el lucro monetario; y por otro lado, como organizaciones del Tercer Sector, las cuales desarrollan acciones colectivas, libremente decididas y autoorganizadas por ciudadanos bajo el paraguas de una organización (formal o informal)».

Es en el tercer sector donde se dan las condiciones más propicias para que la potencia del cibermundo sea mejor aprovechada; y viceversa, es el mejor lugar para que el cibermundo se ensanche y profundice. No en vano, la sociedad del cibermundo se rige por pautas sociales, económicas y políticas muy similares a los dos tipos de entornos sociales mencionados en la introducción: el entorno cotidiano, propio de la sociedad civil; y el de los colectivos que, dotándose de normas y estructuras propias, disponen de recursos compartidos, tanto para proyectos de vida en común como para objetivos más específicos. En ambos casos la estructura de las redes es mucho más distribuida que en las instituciones y en los entornos empresariales, de ahí que se den ricos procesos de retroalimentación y creación entre tecnologías cibernéticas y tecnologías sociales.

Llevado lo anterior hasta sus últimas consecuencias, podríamos hallarnos ante la hipótesis de una incompatibilidad estructural entre los sectores del mundo político y de las empresas convencionales respecto del cibermundo abierto y distribuido. Algunos de los datos que la justifican provienen de investigaciones recientes sobre las diferencias entre los mensajes transmitidos en la Red de arriba abajo y los que circulan por las redes de confianza entre personas que se conocen. Mientras las consignas políticas y campañas publicitarias (lanzadas vía Twitter u otras redes sociales) tienen un muy limitado efecto, solo perceptible entre los que ya están convencidos, los cambios de actitud son notables cuando los mensajes llegan a través de contactos directos entre personas que ya se conocen (Bond et al., 2012; Toret, 2013).

En resumidas cuentas, el tercer sector no es un resto informe frente a la preeminencia de los otros dos. Al contrario, constituye un verdadero tercer elemento que desestabiliza y rompe con la dicotomía público-privado, cada vez más encerrada en sí misma. En este sentido es inherente al desarrollo de un cibermundo del tipo que hemos descrito que el estatuto del procomún sea el principio de relación de las personas con las cosas. Según Benkler (2015a: 98-99) el procomún es «una específica forma institucional de estructurar el derecho 
de acceso, uso y control de los recursos» que, en lugar de asignar a un propietario el control exclusivo de los recursos, establece que «cualquier miembro de un grupo (más o menos de finido) de personas puede usar o disponer de los recursos regidos por el procomún, de acuerdo con unas normas que pueden ir desde el 'todo vale' a reglas formales escrupulosamente articuladas que se aplican de modo efectivo».

En última instancia, la cuestión que interesa subrayar aquí es lo siguiente: en el cibermundo empieza a surgir una comunidad de artefactos que dispone ya de normas propias en cuanto a la conservación y ampliación de su potencia, que muestra incipientes capacidades de autorregulación y que apunta una tendencia a componerse con los objetos tangibles que pueblan el geomundo. Del mismo modo que ocurre todavía con ciertas explotaciones fores tales, espacios de caza y pesca o sistemas de regadío, el procomún implica la composición de dos comunidades, la de los cibercuerpos y la de los internautas, cada una con sus propias normas, que deben relacionarse mediante reglas de beneficio mutuo. De esta manera se trastoca la clásica relación de propiedad al no haber ya tanto dominio de una parte sobre otra como cuidado mutuo.

Finalmente, y como también sucede en el geomundo, el principio de que ambas comuni dades deban funcionar y considerarse como totalidades autorreguladas y abiertas conduce a que en su comunidad los propietarios humanos deban aprender a regirse mediante el autogobierno y la democracia participativa.

\section{Ética}

Cuando Pekka Himanen (2002) escribió su obra de referencia sobre la ética hacker, tomó como referencia La ética protestante y el espíritu del capitalismo, donde Max Weber (2012) desarrolla tres temas: el trabajo, el tiempo y el dinero. Para los dos primeros Weber se remonta a las reglas de los monasterios de la Alta Edad Media. No se puede decir que estas reglas fueran expresiones de modos de vida, como normas interiorizadas, más bien eran guías morales para disciplinar unas conductas que espontáneamente seguían tendencias muy distintas. Esta es la gran diferencia de la moral respecto a la ética, según los conceptos que tenemos de ambas: el deber ser, dictado por una norma previa, externa y trascendente frente a la potencia del ser, desarrollo inmanente de «lo que puede un cuerpo» en la expresión de Baruch Spinoza (2009), que ahora podríamos actualizar como «lo que pueden muchos cuerpos»). 
De acuerdo con el criterio expuesto, Himanen (2002) expresa una verdadera ética, no una supuesta ética universal de validez atemporal sino una que es propia de este tiempo, el de la imbricación creciente entre cibermundo y geomundo. En este sentido, la dificultad de exponer una ética concreta es cómo explicitar con palabras lo que de sí es implícito, sin convertirlo en un manual de instrucciones. Consciente de ello, Himanen se sitúa muy cerca de lo que acontece, mostrando más que argumentando o prescribiendo. Por ello es posible que a toda ética no le quepa otra opción que ser inteligente y delicadamente materialista para no traicionar la inmanencia.

¿Cuál podría ser el término adecuado para la ética hacker? Creemos que creatividad es un buen candidato. $\mathrm{Y}$ desde luego creatividad en un sentido muy materialista, atenta a la emergencia de propiedades nuevas (tales como las que nos muestran desarrollos científicos ya en plena madurez, como las matemáticas no lineales, la física de los procesos disipativos o las teorías de la emergencia en la evolución de los seres vivos). No una creatividad del origen, para la cual lo único que queda es gestionar lo dado de una vez y para siempre; ni mucho menos una creatividad sometida a una lógica de la innovación que remite en última instancia a la moral de la competitividad (YProductions, 2009: 55-78). Hablamos de lo contrario: una creación continua y una experiencia autotransformadora cuyas motivaciones son la pasión lúdica, el cuidado por aquello que se genera en común y el placer del don, que a su vez provoca y desencadena nuevos procesos creativos.

Al mismo tiempo, la creatividad comporta una actividad de tipo destructivo: el cuestio namiento de las propias y habituales condiciones de partida. Así, se parte de una situación de tabula rasa que no debe confundirse ni con un origen inmaculado (como si el pasado hubiera desaparecido) ni con el ensimismamiento que necesitaría un supuesto estrato superior reservado a unos pocos privilegiados. De lo que se trata más bien es de vaciarse de impera tivos exógenos sobre lo que debe ser y ponerse en una situación de receptividad máxima, tanto hacia lo que nos rodea como hacia lo que nos invita nuestro propio cuerpo. Ya no se trata de transformación sino cotransformación y por tanto autotransformación. Es decir creatividad, ahora más que nunca, cuando las criaturas artificiales adquieren una potencia nueva como integrantes del cibermundo en expansión. 


\section{Las mediaciones y el capital}

Lo que acaba de comentarse es solo uno de los mundos posibles, un modo específico de existir que, al igual que los espacios sociales de lo cotidiano no mercantilizado y las comu nidades que desde siempre han pugnado por su autonomía, contrasta fuertemente con la sociedad del homo oeconomicus, la sociedad del capital.

Las tecnologías P2P que permiten relaciones directas y simétricas entre cualesquiera nodos son simplemente la consecuencia de la estructura distribuida que caracterizó internet desde sus inicios, cuando se inventaron los protocolos TCP/IP, con el fin de que la Red fuera muy flexible y que los agentes a los que debería servir tuvieran el mayor protagonismo y libertad posibles. Así puede afirmarse en términos generales que el soporte del cibermundo es sustancialmente neutral en relación con los flujos que circulan por él. Ello contrasta con lo que ha sido habitual en los sistemas de comunicación de masas previos a internet, donde siempre ha existido un agente capaz de interferir en la manera en que circula la información y en el contenido de la misma.

Sin embargo, junto a los medios de comunicación existe otro poder de mediación social, formidable y a la vez sutil: el capital que se intercala entre las cosas y las personas y entre las mismas personas, desplazando todas las formas previas de mediación o poniéndolas a su servicio para después eliminarlas. En la actualidad le toca al Estado ser desplazado como gran mediador entre el bien de interés común (ya enteramente asimilado a la propiedad pú blica) y los intereses particulares. Tipos de mediación fundamentales del capital son los medios de producción entre los trabajadores y los bienes y servicios producidos, así como, simétricamente, los bienes y servicios de consumo entre las personas y sus necesidades (incluyendo cuidados y afectos).

La mercancía en general, como mediador universal entre todas las personas, así como entre criaturas humanas y no humanas, es un superdispositivo que construye subjetividad inconsciente (catalización de deseo) y subjetividad preconsciente (producción de sujetos sociales), a la vez que crea necesidades y mundos posibles. Y como conformadora de conductas, desde lo que necesitamos biológica, social y subjetivamente para el modo de vida al que estamos habituados, es instrumento de la biopolítica. Ahí es donde confluyen economía y política. En este sentido hablamos de un poder de composición, un poder-entre, diferente aunque coexistente con el poder-sobre de dominación. 
El capitalismo no deja de producir mediadores que son exteriorizaciones instrumentales de las capacidades humanas, de ahí que se le atribuya la virtud de gran favorecedor del progreso tecnológico. Así, por ejemplo, la limpieza doméstica realizada por sirvientes se ha ido convirtiendo en un trabajo que es ejercido por personas ajenas al entorno familiar a cambio de algo parecido a un salario; luego eso mismo lo realiza una empresa, y finalmente lo hace un robot automático, un artefacto sujeto a una tecnología mecánica y a una tecnología comercial (el marketing, con lo que conlleva de publicidad, servicio posventa, obsolescencia planificada, venta a plazos, etc.), por completo fuera del control de los usuarios. Se trata de una tendencia general cuyo resultado es la sustitución de los agentes humanos, siempre problemáticos, por artefactos dóciles y automáticos.

Ahora bien, como muestra el ejemplo citado, no es imprescindible una tecnología exteriorizada en forma de artefactos cuando las mismas personas se convierten en simples mediadoras, separadas tanto de lo que producen como de los destinatarios de esa misma producción, alquilando un tiempo de trabajo que para ellas carece, como consecuencia, de todo sentido salvo el de conseguir el dinero para poder sobrevivir. El tiempo de consumo, objeto de las tecnologías comerciales ya mencionadas, también se vuelve productivo, no solo en un sentido sistémico (como espacio plenamente económico acoplado con el de la producción propiamente dicha) sino en su función de retroalimentación de la producción con información técnica y estratégica. Nociones como la de «consumo productivo» (Echeverría, 1994: 63-80) o el de «retroproducción» (Serrano, 2010: 193) contribuyen a profundizar en esta concepción expandida del tiempo de consumo.

De un modo general, las entidades (cualquier tipo de materias primas, sean minerales, coles, ideas o seres humanos) dotadas del movimiento propio de su ser en su ecosistema natural, son separadas unas de otras y extraídas de ese contexto. A continuación son conectadas de nuevo en una red de mediaciones preestablecida (una aleación, el sistema ali mentario, una patente, el mercado laboral...) que produce una movilidad extraordinaria pero definida y regulada desde un exterior. A esta situación es aplicable la distinción que hacía Aristóteles (1995) entre «movimientos naturales», cuyo principio es interno a lo que se mueve, y «movimientos violentos», que precisan una acción continuada (entendida como regulación) desde un agente exterior. Una vez suprimido el movimiento natural es fácil asegurar que el movimiento, es decir la vida, está ausente en la cosa. Lo cual, en términos económicos, equivaldría a asegurar que la riqueza solo la produce el capital.

En el caso de las criaturas humanas, cuando toda relación social tiende a ser capturada por mediaciones cada vez más ajenas se produce el encapsulamiento de los individuos y el abandono a su soledad. El mecanismo de retroalimentación en que se funda la construcción 
de la subjetividad se debilita o desaparece. Eso ocurre cuando el afectar y el ser afectado, y como consecuencia la autoafectación, dependen de una estructura de mediadores que se interpone entre el otro y yo. De igual manera, si el autogobierno, personal o colectivo, se nos dice que es inviable es porque antes se han suprimido las condiciones que lo hacían posible, dando pie a un pensamiento circular (compartido por igual por gobernantes y gobernados) que se muestra incapaz de saber qué está ocurriendo y qué le ocurre como tal pensamiento.

\section{Cibercapitalismo}

En el segundo epígrafe, dedicado a la potencia del cibermundo, se han tratado, aunque de un modo desigual, cuatro tipos de bucles que recorren la problemática asociada al surgimiento del cibermundo:

- A nivel interno, el relativo a las infraestructuras, las relaciones entre las llamadas «capa lógica» y «capa física» (Benkler, 2015a: 438) del sistema de comunicaciones. El proceso que media entre comienzos de los $70 \mathrm{y}$ finales de los 90 del siglo $\mathrm{XX}$ dejó resuelta (de momento) la actual configuración de internet. Otras alternativas siguen siendo posibles, pero la expansión y fertilidad del sistema actual le debe mucho a las ideas de red abierta y distribuida que fueron aplicadas entonces.

- La relación entre las partes humana y no humana constituye otra problemática que en este caso desborda ampliamente el cibermundo. Especialmente conflictivo es el asunto de las convenciones sociales sobre el concepto de propiedad, puesto en crisis por el renovado interés en el procomún, que en el cibermundo se traduce en el carácter libre y abierto de las tecnologías y que tiene como consecuencia la aparición de los «públicos recursivos» (Kelty, 2008: 3).

- Cibermundo y geomundo forman un tipo diferente de bucle, en rapidísima expansión y que está llegando a una cierta madurez en lo que atañe a los grandes dominios de lo político y lo económico.

- El cuarto bucle es transversal a los tres anteriores y se puede resumir en la fórmula yo/otro. Es el gran tema de la subjetividad que en la actualidad ya no se puede presentar como algo que atañe solo al interior de los individuos sino que cuestiona la asentada distinción entre lo individual y lo colectivo. 
En este complejo panorama vamos a proponer algunas reflexiones en relación con el tercer bucle citado, el que vincula dinámicamente el cibermundo con el geomundo, considerando que el cibercapitalismo inventa mediadores entre ambos mundos para así controlarlos.

Por si fueran pequeños los efectos de la actual crisis económica (y, en un contexto más amplio, las crisis política, energética, medioambiental, de biodiversidad y, por supuesto, la crisis del pensamiento) el cibermundo, acaso de un modo no casual, también representa un reto de primer orden para la supervivencia del capitalismo que conocemos. A continuación esbozamos algunos de los aspectos más críticos que focalizan los conflictos actuales.

En primer lugar, encontramos las capacidades de recepción y emisión (y el procesamiento que media entre ambos momentos), condición para una especie de protosubjetividad, lo que a su vez abre a la autotransformación. El capitalismo no es un régimen compatible con la autonomía real de los componentes en las esferas de la producción y el consumo.

Otro aspecto crítico es el carácter abierto de los medios tecnológicos, sobre los que es crecientemente difícil reclamar un monopolio jurídico, de producción o de uso. Eso favorece un acceso cada vez mayor al conocimiento disciplinar $\mathrm{y}$, lo que puede ser más importante, estimula la proliferación de saberes menores y prácticos, así como tecnologías intermedias al servicio de una creatividad de amplia base social, con el correspondiente incremento de las capacidades para la propia autonomía.

Junto a ello, el acervo creciente de libre disposición de muchos de los medios y recursos del cibermundo (bienes comunes protegidos legalmente contra la apropiación privada) cons tituye una cultura comunal que, como se ha expuesto, implica prácticas democráticas de tipo participativo. Todo esto, además, construye las bases operativas, jurídicas y económicas de una circulación libre de los excedentes, oponiéndose a la apropiación privada de los bienes y a la creación (artificial) de escasez.

En la misma línea, la red distribuida ha llegado a una cierta madurez tecnológica con la aparición de las aplicaciones P2P, las cuales posibilitan fenómenos emergentes de enormes consecuencias (y ello mucho más allá de la consabida compartición de archivos). Aunque dichos fenómenos no tengan una presencia muy extendida, en cambio sí nos muestran un panorama perfectamente factible en cuanto no son meras posibilidades más o menos teóricas. Precisamente este es el principio sobre el que se apoya toda la argumentación que se ha expuesto en el epígrafe segundo, que ahora sintetizamos en torno a cuatro rasgos: la naturaleza indeterminista de los procesos, las identidades múltiples y en continuo cambio, la autorregulación que prescinde de centralidad organizativa y la capacidad transformadora 
desde abajo. En correspondencia con lo anterior quedan seriamente cuestionados dos principios fundamentales de la mentalidad dominante, los de la centralización y representación.

Con respecto a la centralización, se apela a ella de diversas formas, aunque siempre bajo la cláusula de la condición de eficacia. En primer lugar, en relación con la gestión de los saberes, con competencias exclusivas para los que legalmente están facultados para practicarlos; del mismo modo se justifica para el control de los procesos productivos y de distribución. En estas formulaciones subyace la idea de la necesidad que tienen todas las criaturas, incluidas las humanas, de ser gobernadas por los que saben. Por otro lado, se asume que la mejor manera de conseguir prosperidad individual, paso obligado para el pro greso social (lo social como suma de individuos), es la economía capitalista, y por tanto la necesidad de la mediación basada en la apropiación privada de la producción colectiva; la riqueza luego fluirá de arriba abajo, de los ricos a los pobres.

Por lo que se refiere al principio de representación, adopta también distintas formulaciones. Así, en relación con el concepto de propiedad, se entiende que el propietario vela por su propiedad, siendo reconocido como su representante por la convención social y jurídica. Como fundamento del edificio político e institucional, se establece la representación y delegación de la soberanía, así como de las facultades para su ejercicio. Por otra parte, el dinero se erige como representación del valor de los bienes producidos. La representación parte de la presunción de que las criaturas representadas, por razones técnicas o por propia incapacidad, no pueden valerse por sí mismas. Al final, en todos los casos, la representación equivale a suplantación.

J. L. Pardo (2011: 271), glosando a G. Deleuze, plantea que «la sociedad capitalista es la primera y la única conocida que se sitúa directamente en la avalancha y no contra ella». La verificación la tenemos en lo que hemos dado en llamar cibercapitalismo, que consiste en aprovechar las cualidades de alcance global, procesamiento casi instantáneo y difusión masiva que caracterizan a los cibermedios. Más aún, este cibercapitalismo consiste en el control y manejo de los aspectos que hemos señalado más arriba: capacidades de recepciónemisión, tecnología abierta, libre disposición de medios y recursos, topología distribuida de las redes.

Si el cibercapitalismo ve comprometida su viabilidad futura será debido a que su base (la economía capitalista clásica) y, sobre todo, su estamento superior (el sector financiero) se enfrentan ya con aporías terminales, pero no por la competencia de una cibereconomía del procomún con la que mantiene ambiguas y provechosas relaciones. Lo prueban los mu chos ejemplos de proyectos híbridos que cuentan con la aportación desinteresada de 
voluntarios o colaboradores que, a cambio, se ven estimulados para desarrollar su creati vidad, difundir sus propias ideas y realizaciones.

¿Cómo aprovechar un dinamismo salvaje? Empleando una metáfora automovilística, se tratará de combinar el freno y el acelerador. El control y limitación de los movimientos, el monopolio de los instrumentos, la identificación y fijación de las criaturas, la reducción o bloqueo de sus capacidades de iniciativa, de conocimiento, de producción, son desde siempre las medidas de freno. Y la infraestructura del cibermundo lo posibilita como nadie podría haberlo soñado antes, disfrutando además de una finura de modulación extraordi naria debido al elemental hecho de que los vehículos de las relaciones son exteriores e independientes de los individuos. Ello no quita que en buena medida dicha infraestructura pueda proporcionar al mismo tiempo recursos para eludir esos frenos.

Las tecnologías sociales relativas a la aceleración igualmente son bien conocidas, incluyendo las derivadas del marketing. Pero también en este caso las características del cibermundo hacen del acelerador un instrumento mucho más potente; como por ejemplo los incentivos a la creatividad y a la formación de máquinas sociales de gran productividad liberadas de las costosas y fastidiosas superestructuras de dirección, control y coordinación.

Haciendo corresponder con los ámbitos de la producción y del consumo distinguimos entonces entre los espacios o plataformas dirigidas a la producción de mercancías, por una parte; y por otra, las llamadas redes sociales que se situarían en el lado del consumo, aunque también producen otros tipos de bienes capitalizables en línea con aquel «mercado de los globos oculares» (Benkler, 2015a: 203) ligado al negocio tradicional de los medios masivos.

Respecto a los primeros, los ejemplos más interesantes y problemáticos son los que Le ssig (2012: 217-268) denomina «economías híbridas». Lo que nos interesa es que se pueden considerar como la exteriorización (tecnologización) de las cuencas de captura de la producción social difusa, verdaderos captadores-condensadores de la creatividad humana y que funcionan ya con regularidad en empresas con un alto componente innovador. No en vano, Lessig se preocupa de que los beneficios que obtienen de esta manera las empresas apenas reviertan en las personas que con su trabajo y entusiasmo colaboran con ellas, para lo cual se sirve de otra metáfora agrícola, la de la «aparcería» (ibid.: 287-291).

No obstante, existe un problema más profundo, dado que muchas de estas iniciativas uti lizan fórmulas capitalistas de explotación laboral por las que un conjunto de colaboradorestrabajadores compiten entre sí para la selección de su aportación (siendo en este caso de un tipo muy extremo, pero cada vez más extendido, dado que generan mínimas obligaciones a las empresas y el contacto es sumamente efímero y distante). Es lo que Benkler (2015b) ha 
criticado con la denominación tentativa de la «Uber-ificación de todos los servicios», alu diendo a la polémica empresa de transporte Uber. El resultado es que el poder de nuevo se concentra y reaparece la consabida relación de los pocos (o uno solo) con los muchos (casi siempre aislados entre sí), típica de los medios de comunicación de masas previos a internet.

En todo caso, son las redes sociales las que mejor nos muestran aspectos esenciales de la cibereconomía. De entrada estos espacios residen en la nube, y desde allí ejercen su función de mediación. Como se sabe, la nube es para muchos propósitos la solución de los problemas de control que plantea una red distribuida; es ahí donde se ubican las ventanas que escrutan la actividad de la mayoría de los internautas y donde residen, cada vez más, los mediadores automatizados entre estos y las personas conocidas, sus trabajos, sus memorias digitales, etc.

¿Qué hay de nuevo entonces? En primer lugar, en el cibermundo la mercancía clásica es sustituida por su imagen, que solo en parte es transmitida por la publicidad: esa es la naturaleza de la mercancía en ese territorio. De ahí la centralidad estratégica del marketing, como saber integral sobre la producción del capital, una especie de metaproducción que transforma a los consumidores en participantes activos de su dinámica socio-económica.

Por lo tanto, para la sociedad del capital su importancia excede en mucho a la estricta mente económica, pues es ahí, en el consumo, donde se produce y reproduce su base humana, especialmente en la formación de la subjetividad social. La creciente penetración de las redes sociales contrasta ciertamente con una productividad económica que no termina de satisfacer las esperanzas de rentabilidad por parte de los posibles inversores y que consigue la mayor parte de los ingresos como mero soporte de la publicidad, por la enorme población que discurre por esos medios. Por ello el número de integrantes de cada red social es importante. De esa cantidad y de la cualidad específica de cada red depende que la publi cidad sostenga su negocio, siendo este un motivo económico objetivo que explica la segmentación y los cercamientos del cibermundo con fuertes consecuencias sociales.

Conviene recalcar que estos mecanismos no son estrictamente novedosos, pues se parecen mucho a lo que todavía ocurre en las calles comerciales céntricas de nuestras ciudades; o también en cualquier medio de comunicación masivo. No obstante el paralelismo del ciberterritorio con el territorio urbano contemporáneo no se limita a este aspecto. El surgimiento del capital como paradigma económico es paralelo a la sustitución del terri torio premoderno por el territorio urbano contemporáneo. Expresado con otras palabras los espacios urbanos modernos, los llamados espacios colectivos (a los que se sumaron los espacios domésticos privados desde los 40 y 50 del siglo XX) han sido el lugar, en modo 
alguno pasivo o neutro (como tampoco lo es el sistema operativo de la Red en relación con el sistema social), de la autoconstrucción y autorregulación de esta sociedad.

Pero la otra cara de la moneda son los específicos públicos recursivos del territorio urbano, los movimientos vecinales, los colectivos mixtos de ciudadanos y técnicos en relación con multitud de problemáticas, las iniciativas temáticas de todo tipo (los huertos urbanos, por ejemplo), el movimiento okupa, etc. Estas iniciativas son muy activas y beligerantes desde los 60, reivindicando, y logrando en no pocas veces, conocimiento y capacidad de decisión sobre el urbanismo como saber y como práctica, es decir, sobre los espacios relacionales por excelencia en el geomundo. Todo esto contribuye a reforzar nuestra idea de la profunda afinidad entre ambos territorios.

En el momento actual, cuando asistimos a una nueva mutación territorial en la que se da una conjunción de lo urbano (geomundo) con el ciberterritorio, el fenómeno parece reproducirse en las redes sociales. Y de igual manera la mercancía ya no son los objetos singulares sino los sistemas de mercancía en copresencia, la atmósfera, el ambiente, inducido decisiva mente por los mismos usuarios o habitantes: comunidades de cibermercancías y comunidades de internautas-consumidores, pero ya bajo el paradigma de la propiedad privada. A estos efectos las redes sociales son espacios de socialización a la vez que de producción capitalista, con el decisivo añadido de que el control y la gestión ya no la ejerce el Estado, como ocurría en el territorio urbano, sino directamente el capital, y de acuerdo con métodos mucho más sofisticados y sistemáticos (Lessig, 2009: 145-192; Cabello, Franco y Haché, 2012: 24-28).

En una primera aproximación, y en relación con la productividad social no directamente económica, podemos considerar las relaciones binarias que se establecen en las redes sociales. Entre individuos tiene mucho interés indagar hasta qué punto este tipo de sociabilidad se cataliza y articula por parte de la mercancía y el consumo y cómo ese tipo de relaciones es estimulado por los instrumentos que brindan las interfaces dispuestas para cada miembro, haciendo algunas opciones fáciles y otras no tanto. La mencionada potencia extraordinaria de la propagación viral en el cibermundo, según vínculos de confianza entre personas, es entonces aprovechada para la difusión comercial, que además se incardina profundamente en la cotidianidad social.

Este es el fondo (social y general) sobre el que se asienta otro tipo de relación binaria, la que establecen las empresas con los consumidores en pos de objetivos más concretos. La estrategia mercadotécnica pasa por crear lazos de confianza, afecto y familiaridad, así como la adhesión a los valores humanos (no estrictamente económicos) asociados con cada marca comercial. El cibercapitalismo aprovecha la exteriorización de las capacidades de recepción 
y emisión a distancia, invitando a que los usuarios opinen, aporten, critiquen, en relaciones biunívocas y de aparente igualdad, fortaleciendo vínculos comunitarios que tienen como centro la mercancía.

La aportación propia del cibermundo a esta lógica no estrictamente nueva es que la despliega de manera masiva y automática, lo cual sintetiza Tim O'Reilly (2006: 8) afirmando que las «externalidades de red por defecto [...] derivadas de las contribuciones del usuario son la clave para el dominio del mercado». Así, nos encontramos ante un seguimiento exhaustivo y a la vez fluido de los movimientos de los cibernautas (en lo que se ha dado en llamar minería de datos) y, lo que es más importante, ante su procesamiento con el fin de ofrecer los productos y servicios más adecuados dependiendo del perfil individual. Estamos pues, ante un sofisticado proceso de fabricación de consumidores según especies y subespecies, cada vez más numerosas y más detalladas, que permiten aconsejar no solo qué podemos comprar sino también quiénes podrían ser nuestros amigos, qué deberíamos conocer y qué opciones vitales se abren ante nosotros. En este punto, cabe mencionar la brillantez de los enfoques que, para resistir a este empuje a la segmentación, optan no solo por el fortalecimiento del anonimato (mediante redes como TOR o buscadores respetuosos de la privacidad como Startpage o Disconnect) sino por la «ofuscación» que haga imposible la generación de perfiles por saturación de la vigilancia y el acopio de datos mercadotécnico (Howe y Nissenbaum, 2009; Brunton y Nissenbaum, 2013).

Dado que el cibermundo es el primer medio de comunicación a distancia en que los muchos son agentes activos, el propósito no es tanto el encierro individual como la creación de colectividades dinámicas, comunidades asociadas a modos de vida susceptibles de ser moldeadas en torno a hábitos de consumo, modas e imaginarios sociales. Ello exige un permanente trabajo de alimentación de los grupos y colectividades, que en gran parte es realizado por sus mismos integrantes, si bien también existen interpelaciones directas de las compañías incitando a los usuarios más perezosos (menos sociables) a usar el servicio o introducir nuevos materiales y comentarios. Del mismo modo, la ausencia de interoperabilidad entre redes sociales inherente a la dinámica de «jardines amurallados» (Cabello, Franco y Haché, 2012: 25) y la voluntad por parte de los gestores de profundizar en la temática que cualifica el espacio en cuestión, explica que la dinámica de retroalimentación sea estabilizante y dirigida hacia los objetivos de los propietarios y gestores: generar y acumular dinero.

Podría decirse que la separación entre espectadores y espectáculo, tan típica de la sociedad de consumo del fordismo, también es cuestionada en la redes sociales, porque espectadores y espectáculo coinciden. La separación ya no pasa por ahí, sino que se repro- 
duce entre lo que es el escenario y la tramoya, entre lo que se ve y lo que lo organiza, justo entre los actores-habitantes y el medio tecnológico (tecnología informática y tecnología so cial y de la subjetividad).

Finalmente hay que considerar un tipo de producción a un nivel superior y diferente de la gestión de las relaciones sociales en el cibermundo, pues se hace muy fácil exteriorizar los instrumentos de la sociabilidad de las redes sociales, automatizando aspectos hasta ahora bajo control directo de sus integrantes. Y con ello se hace factible cartografiar con todo lujo de detalles la topología de la relaciones sociales, haciendo del capital social (el que depende del valor relativo de las posiciones o nodos en una red social) un capital directamente monetario.

Además de los modos de producción, hay que atender a los modos de distribución-comunicación, que siempre han sido propiedad del capital o bien controladas por el Estado. Las decisiones que en sus comienzos hicieron de las infraestructuras del cibermundo medios neutrales y abiertos, es decir, utilizables por muchos internautas pagando por el servicio un alquiler asequible, son las que han hecho el cibermundo tal como lo conocemos. Frente a ello, la llamada nube permite que lo que antes estaba distribuido empiece a recentralizarse, y ello por lo que respecta tanto a los medios de producción como a los medios de distribución-comunicación. No importa que esas capacidades generadas por multitud de internautas no pasen a ser propiedad privada de los dueños de esos espacios nubosos: basta el control sobre ciertos puntos críticos para que se esfume la privacidad, para que la autonomía de los usuarios se vea comprometida y para que los productos de su actividad puedan ser capturados y explotados comercialmente en ajenos y remotos espacios. Acaso baste mencionar las repercusiones del cierre de Megaupload el 19 de enero de 2012 para ahorrarnos una explicación más pormenorizada de esta idea.

\section{Conclusión}

La actividad superlativa y la explosión de creatividad que se dan en el cibermundo corren el riesgo de sufrir la masiva apropiación y retención de sus productos. Y cuando al otro lado del circuito económico se ofrecen los bienes de consumo, otra vez se reproduce la separación entre las personas y las cosas, y ello de un modo mucho más radical de lo que sucedía antes de internet, pues lo que se tiende a vender es solo el derecho a su uso, no la propiedad. Todo lo que esta conlleva de disponibilidad de utilización y disfrute, y en relación con nues tros semejantes, la libre enajenación, más el préstamo y la compartimentación, quedan no 
solo prohibidos y perseguidos de la manera más extrema, sino suprimidos de raíz (Cabello, 2010).

Lo dicho no significa que todas las redes sociales, empresas híbridas y demás espacios que combinan actividad empresarial con una proyección positiva hacia los habitantes del cibermundo acaben amenazando la potencia de este. Pero las posibilidades tecnológicas están abiertas y disponibles: las tecnologías informáticas y las propias del marketing son bien conocidas desde hace tiempo; en cuanto a las relacionadas con la subjetividad social, poco a poco se han ido construyendo y empiezan a ser exitosas en múltiples ámbitos de la Red. Al hablar de esta tecnología nos referimos a la que nos convierte en colaboradores, a veces en tusiastas, del control social que precisa el capitalismo en su actual fase de «movilización global» (López-Petit, 2009), por la que toda forma de vida, y no solo la humana, es puesta a trabajar y dar beneficios.

Asistimos a una extraordinaria proliferación de iniciativas que fundamentan su creatividad en las propiedades del cibermundo, así como otras que exploran ese prometedor continente en el que los cuerpos digitales se componen con los cuerpos de materia orgánica y de materia mecánica. Pero si la creatividad se pone al servicio de la rentabilidad económica, hay muchas probabilidades de que la parte encargada de los negocios capture y desnaturalice la parte del trabajo inventivo, incluyendo a esa red de voluntarios cuya contribución no está motivada por el lucro o a esos habitantes con una parte considerable de su vida discurriendo en las redes sociales.

Recapitulando lo que se ha expuesto en este artículo, y con la intención de dejar abierto el debate, proponemos algunos interrogantes para empezar a discernir si la tendencia general, pero también las distintas experiencias e iniciativas concretas, apuntan en una u otra dirección de la bifurcación (o bien si se mantienen en una virtuosa equidistancia, aprovechando lo mejor de ambas partes, si es que eso es posible):

- ¿Hay retroalimentación positiva, es decir, apertura a nuevos e imprevisibles mundos, aparte de la retroalimentación negativa o estabilizante, o solo se da esta última, reproduciendo hasta su agotamiento el estado actual de cosas?

- El excedente, producto natural de cualquier comunidad de criaturas humanas y no humanas, ¿revierte en la comunidad o es cercado, capturado y acumulado por entidades privadas?

- ¿Se genera abundancia para disfrute general o esta solo forma parte de la fase previa de la escasez (escasez económica y escasez social, la de los pocos que deciden sobre la vida de los demás)? 
- ¿La creatividad crea creatividad o es solo un instrumento más, tal vez una coartada, o peor todavía, un medio para anular la creatividad de los demás? 


\section{Referencias}

Aristóteles (1995). Física. Madrid: Gredos.

Benkler, Y. (2015a). La Riqueza de las redes. Barcelona: Icaria. Extraído de:

$<$ http://www.icariaeditorial.com/pdf_libros/la\%20riqueza\%20de\%20las\%20redes.pdf $>$

Benkler, Y. (2015b). Challenges of the Shared Economy. Conferencia en el Foro Económico de Davos. Extraído de:

$<$ https://www.youtube.com/watch?v=mBF-GFDaCpE $>$

Berners-Lee, T., Hendler, J. y Lassila, O. (mayo de 2001). The Semantic Web. Scientific American, 284 (5): 34-43.

Bond, R.M. et al. (13 de septiembre de 2012). A 61-million-person experiment in social influence and political mobilization. Nature, 489 (7415), 295-298. Extraído de:

$<$ http://www.nature.com/nature/journal/v489/n7415/full/nature11421.html>

Brunton, F. y Nissenbaum, H. (2013). Political and Ethical Perspectives on Data Obfuscation. En M. Hildebrandt y K. de Vries (eds.). Privacy, Due Process and the Computational Turn (pp. 164-188). Nueva York: Routledge.

Cabello, F. (2010). Cuando "el código es la ley": Sociedad de control y arquitectura del ciberespacio. Faro, 11: 1-9.

Cabello, F., Franco, M.G. y Haché, A. (2012). Hacia una web social libre y federada: el caso de Lorea. Teknokultura, 9 (1), 19-43. Disponible en:

$<$ http://revistas.ucm.es/index.php/TEKN/article/view/48218>

DunBar, R.I.M. (1993). Coevolution of neocortical size, group size and language in humans. Behavioral and Brain Sciences, 16 (4), 681-735.

ECHEVERríA, J. (1994). Telépolis. Barcelona: Destino.

Engelbart, D. (1962). Augmenting Human Intellect: A Conceptual Framework. Extraído de: $<$ http://web.stanford.edu/dept/SUL/library/extra4/sloan/mousesite/EngelbartPapers/B5_F18 _ConceptFrameworkInd.html>

Haché, A. (2011). Under the radar. Luxemburgo: Publications Office of the European Union. Extraído de:

$<$ http://ipts.jrc.ec.europa.eu/publications/pub.cfm?id=4339> 
Hendler, J., Berners-Lee, T. y Miller, E. (octubre de 2002). Integrating Applications on the Semantic Web. Journal of the Institute of Electrical Engineers of Japan, 122 (10): 676-680.

Himanen, P. (2002). La ética del hacker y el espíritu de la era de la información. Barcelona: Destino.

Howe, D.C. y Nissenbaum, H. (2009). TrackMeNot: Resisting Surveillance in Web Search. En I. Kerr, I., Lucock, C. y Steeves, V. (eds.) Lessons from the Identity Trail: Anonymity, Privacy, and Identity in a Networked Society (pp. 418-436). Oxford: Oxford University Press.

Kelty, C. (2008). Two Bits. Durham: Duke University Press. Extraído de: $<$ http://twobits.net/pub/Kelty-TwoBits.pdf $>$

Lessig, L. (2009). El Código 2.0. Madrid: Traficantes de Sueños.

Lessig, L. (2012). Remix. Barcelona: Icaria. Extraído de: $<$ http://www.icariaeditorial.com/pdf_libros/REMIX.pdf $>$

López-Petit, S. (2009). La movilización global. Madrid: Traficantes de sueños.

Pardo, J. L. (2011). El cuerpo sin órganos. Presentación de Gilles Deleuze. Valencia: PreTextos.

O’Reilly, T. (2006). Qué es Web 2.0. Telos. Extraído de: $<$ http://conceptemc2.org/gnu-web2.0.pdf $>$

Serrano, E. (2010). La abundancia que crea escasez. Barcelona, Erasmus Ediciones.

SpinozA, B. (2009). Ética. Madrid: Trotta.

J. Toret (Coord.) (2013). Tecnopolítica: la potencia de las multitudes conectadas. Barcelona: UOC. Extraído de:

$<$ http://journals.uoc.edu/index.php/in3-working-paper-series/article/view/1878>

Weber, M. (2012). La ética protestante y el «espiritu» del capitalismo. Madrid: Alianza.

Winner, L. (1977). Autonomous Technology. Cambridge (MA): MIT Press.

WINNER, L. (2008). La ballena y el reactor. Madrid: Gedisa.

Y PRODUCTIONS (2009). Innovación en cultura. Madrid: Traficantes de Sueños.

_-Última consulta de todas las páginas web citadas: 16 de abril de 2015._- 
